\title{
Research on Development Status and Problems of Rural E-Commerce Logistics
}

\author{
Fuyan Yang ${ }^{a}$, Xiaodong $\mathrm{Li}^{\mathrm{b}}$ \\ School of Logistics, LinYi University, Linyi 276000, China; \\ ayangfuyan1@163.com, b15653976597@163.com
}

Keywords: E-Commerce Logistics, Rural, Logistics Development, Development Status.

\begin{abstract}
In recent years, with the development of electronic commerce, rural e-commerce has become the focus of government, enterprise and society. Logistics is the foundation of the development of electronic commerce, However, the conditions of rural economic development, traffic network and internet penetration restrict the development of rural e-commerce logistics. With the attention of the country to the rural e-commerce and the gradual deployment of the outlets of the large logistics enterprises to the rural villages and towns, the logistics of the rural e-commerce has received extensive attention. From the perspective of rural economic construction and self-development, the development of e-commerce logistics is also an inevitable trend. Therefore, the research on the development of rural e-commerce logistics is very important for the construction of new countryside, the scale and market expansion of logistics enterprises, and the construction of rural economy.
\end{abstract}

\section{Introduction}

In modern society, informatization has become an essential driver for national economic development and social development. E-commerce has taken up the dominant position of China $\mathrm{S}$ national economy, and it has penetrated into daily life. With the development of information technology and the popularization of Internet, e-commerce has made great progress due to its unique advantages over time and space, convenience, low cost and wide spread in China. As an important part of e-commerce, logistics has aroused great concern. This paper analyzed existing problems in development of rural e-commerce and logistics in China, deepens our understanding of rural e-commerce, and recognizes the direction of the development of e-business logistics in rural areas. On the basis of these problems, it came up with pertinent recommendations development of e-business logistics in rural areas. We hope that our research has a positive significance to the development of rural e-commerce and logistics enterprises.

\section{Development Status of E-Business in Rural Areas}

Rural e-commerce refers to the whole process of transferring the products that are easy to get from rural economic activities to the market and completing transactions by using simple, fast and low-cost electronic communication mode. E-commerce development must have support of well-established logistics network, and agricultural product logistics development should receive much attention. On December 12-23, 2014, the National Agricultural Work Conference was held in Beijing and it proposed developing agricultural product e-commerce, accelerating development of agricultural informationization, promoting reform of agricultural scientific and technological system, and speeding up agricultural scientific and technological innovation. In the report of the government work in 2016, it mentioned the promotion of the development of rural e-commerce. In addition, the disclosure of the next five years plans to implement 100 major projects and projects, referred to the realization of village-to-village connection. The support of national policy, make the rural electricity supplier becomes more broad prospects. In the context of policy helping the development of rural electricity, the Internet giants Jingdong and Alibaba have already begun to deploy. The former introduced the "3F strategy" of industrial products entering the rural strategy, the rural financial 
strategy and the fresh electricity business strategy, the latter is planning to invest tens of billions, and set up covering one thousand counties and one hundred thousand administrative villages in the service system.

\section{Lack of Rural E-Commerce Logistics Resources}

Along with the development of e-commerce, the logistics industry is developing rapidly. There are many small and medium-sized logistics companies. The size of the company also determines its scope of service is limited. Most of the logistics companies are service to the city level, and the township is their development goal. A powerful logistics company can serve the county level, such as Shun Feng, Yuan Tong, Shen Tong and Zhong Tong express.

At present, there is lack of service platform for rural e-commerce logistics informationization. There are various problems in information of rural e-commerce and logistics. Firstly, rural areas are scattered, so logistics information is highly decentralized. Secondly, many small companies have not established excellent logistics information channel, data are independent, resources are not shared, thus they fail to realize information exchange and interconnection. Thirdly, there is no large enterprise, and no leading effect. Therefore, we should pay attention to the logistics of rural e-commerce.

\section{Rural E-Commerce Logistics Relying on China Post}

China post was established in 2003, with a long history and close to the rural areas. Its advantages are more obvious, such as the support of the state, the integrity of the system, the scattered coverage of the region, the high popularity rate and the good reputatio, but there are still some shortcomings:

1. Delivery is not in time: China post is relatively large, its size determines its performance, but the performance of the poor response to the effectiveness of time. The time of the goods on the road is long, not only affects the time of delivery, but also may affect the quality of the goods.

2. Long delivery effect: The effectiveness of the collection is not guaranteed, the customer psychology will be affected, there is a kind of anxiety, especially in the rural areas of e-commerce is not too aware of the situation. The shorter the time of receiving the goods, the customers feel that the time of the goods on the road is short, and the customers will receive the goods to eliminate the anxiety. The uneasiness of the customer is usually more obvious in the first experience of online shopping.

3. Difficult to guarantee the quality of goods: The longer the goods are on the road, it is more difficult to be guaranteed the quality of the goods. If the quality of the goods is not guaranteed, the failure to believe in the customer will affect the success of the transaction and then affect the transaction rate. At the same time, it will also affect the evaluation of the use of goods. This will deteriorate restless feeling of both buyers and sellers.

\section{Problems in the Development of Rural E-Business in Areas}

\subsection{Lack of infrastructure}

Most of the rural areas are in remote places, traffic is extremely inconvenient, Logistics is the last link of e-commerce. In order to successfully complete e-commerce transactions, it is bound to spend a lot of capital in remote areas. Except remote areas, the construction of village-to-village connection project has basically covered rural areas of China, but there are still some villages that have no connection roads. $\mathrm{n}$ line with existing situations of rural areas, it is necessary to strengthen construction or rural road network. Most rural roads have realized interconnection, but they are seriously damaged and out of repair for long years.

\subsection{The Popularity of the Internet is Low in Rural Areas}

As a medium of information dissemination in the process of e-commerce transactions, the Internet is also an important tool for e-commerce logistics information and has a vital role. At present, the prevalence of Internet in rural areas is low, the size of rural Internet users is not large and the 
infrastructure construction of the network is insufficient. As of the end of December 2017, China's rural Internet users accounted for $27 \%$ of the scale of 209 million; Urban Internet users accounted for $73.0 \%$, the scale of 563 million. The penetration rate of Internet in urban areas of China is $71 \%$, and that of the Internet in rural areas is $35.4 \%$. It can be seen from the above data that the Internet penetration rate in rural areas is low.

\subsection{Insufficient Professional Personnel}

There are insufficient professional personnel of logistics in rural areas. Most rural areas are relatively remote, both transportation and communication are relatively inconvenient, and the economic level is not high, the economic development is slower. Influenced by these harsh objective conditions in the rural areas, it is difficult for rural areas to introduce professional logistics personnel.

\section{Suggestions for the Development of Rural E-Commerce Logistics}

\subsection{Absorb Professional Talents}

The rural e-commerce needs the participants to have higher professional quality and knowledge literacy. As far as the current situation of farmers in China, it seems unrealistic to make them have a higher level of cultural knowledge in a short time. Therefore, the government should set up e-commerce information service center, then cover the service points of various villages, and introduce high-level managers and compound talents to operate. Rural areas should make well preparation for cultivation and introduction of professional personnel for modern rural logistics, so as to provide technical guidance and talent reserve for the development of rural e- commerce and logistics.

\subsection{Set up the Logistics Center to Solve the Problem of Distribution}

In the report of the government work in 2018, it mentioned the promotion of the development of rural e-commerce. Government is going to strengthen policy guidance and financial support for rural areas, to promote construction and improvement of rural infrastructure, and accordingly promote coordinated development of rural and urban economy. Government is going to strengthen infrastructure construction for rural e- commerce logistics.

The ultimate success of rural e-commerce depends on logistics. Therefore, e-commerce needs the support of logistics enterprises. These large logistics companies can establish their logistics system and channels in rural areas, and then sell their products to rural areas. We can try in the following aspects:

1. Supermarket instead of receiving

An express cooperation in the village supermarket, not only can solve the problem of logistics delivery is not timely, but also can increase the supermarket traffic, improve customer purchase rate. Farmers can take their own goods while buying their living items. This is a good way for both the supermarket and the consumer.

2. The establishment of the rural service center

The government should invest in the establishment of an e-commerce service center. $n$ the e-commerce service center, farmers can buy their favorite goods on the Internet, and can also sell agricultural products to the outside. All express service can be carried out through the service center.

3. Intelligent locker

In a village without supermarket cooperation, the villagers' committee will set up the express intelligent locker. The courier only needs to input the phone number of himself and his customers, then scan the express number to send the express to the cabinet and send a password to the customer. In the central control panel, enter the password and put in the coin, you can take out the express

\section{Conclusion}

Rural e-commerce will maintain high speed development in the future. However, the conditions of rural economic development, traffic network and internet penetration restrict the development of rural 
e-commerce logistics. This paper analyzed existing problems in development of rural e-commerce and logistics in China, recognizes the direction of the development of e-business logistics in rural areas. On the basis of these problems, We put forward some suggestions. We hope that our research has a positive significance to the development of rural e-commerce and logistics enterprises.

\section{References}

[1]. The 41th China Statistical Report on Internet Development[C]. China Internet Network Information Center.2018.1

[2]. X Chen,J Zhou. The Research on the Interaction Effects of Rural Logistics and Economic Development[C]. International Conference on Enterprise Information Systems.2011, 3 (6) :167-171

[3]. ZHU Hong-chang, LI Yi-yi, DU Xiang-yu, GUO Han. Development Status, Problems and Promotion Countermeasures of Rural E-commerce Logistics in China[J]. Logistics Engineering and Management.2018

[4]. DM Bai, WQ Shao, YL Zhou, Y Chen, HG Tao. Research on Collaborative Development of E-commerce and Rural Logistics in the "Internet Plus" Era. Logistics Sci-Tech[J].2016

[5]. Lixin Tang. Problems in Development of $\mathrm{R}$ ural E-commerce and Logistics and $\mathrm{R}$ ecommendations. Asian Agricultural Research . 2016,8(12): 41 - 42,47

[6]. Rural E-commerce and New Model of Rural Development in China: A Comparative Study of "Taobao Village" in Jiangsu Province. Asian Agricultural Research [J]. 2015,7(11): 35 - 37,46 